\title{
COMPETIÇÃO INTRAESPECÍFICA EM BOOPHILUS MICROPLUS ${ }^{1}$
}

\author{
INTRA-SPECIFIC COMPETITION IN BOOPHILUS MICROPLUS
}

\author{
Andreia Passos dos Santos ${ }^{2}$ John Furlong ${ }^{3}$.
}

\section{RESUMO}

$O$ presente trabalho foi desenvolvido no Campo Experimental da Embrapa Gado de Leite, Coronel Pacheco, Minas Gerais, Brasil, tendo como objetivo a verificação da ocorrência de competição intra-específica durante a fase parasitária do carrapato bovino Boophilus microplus e a confirmação da correlação positiva entre o peso da fêmea ingurgitada e o peso da massa de ovos. Foram feitas observações em bovinos infestados naturalmente e experimentalmente, com cargas parasitárias e intervalos diferenciados. Os animais infestados permaneceram em baias individuais durante todo o período de queda das fêmeas ingurgitadas, para que estas pudessem ser coletadas diariamente. As diferenças observadas entre as médias de peso das fêmeas ingurgitadas, no decorrer dos dias de queda, sugeriram a ocorrência de competição durante a fase de alimentação. Observou-se também que o potencial de oviposição está diretamente relacionado a sua capacidade de alimentação.

Palavras-chave: Boophilus microplus, competição, eficiência reprodutiva, eficiência nutricional.

\section{SUMMARY}

This study was developed in the Experimental Station of Embrapa Dairy Cattle, Coronel Pacheco, Minas Gerais, Brazil, and had the aim of verifying the occurrence of intraspecific competition in the cattle tick Boophilus microplus during its parasite life and to confirm the relation between the weight of engorged females and the egg mass laid. Observations were done with cattle naturally and experimentally infested with different quantities of larvae during different intervals of time. The infested animals remained in individual stalls for the whole period of engorged females drop-off, in order to collect them daily. The observed differences among weight of engorged females during drop-off days suggested the competition occurrence during the feeding phase. It was also seen that the oviposition potential of an engorged female is directly related to its feeding capacity.

Key words: Boophilus microplus, competition, egg production index, nutrient index.

\section{INTRODUÇÃO.}

O carrapato bovino Boophilus microplus apresenta no seu ciclo biológico, duas fases: uma parasitária e uma fase de vida livre. A primeira dura em média 22 dias e caracteriza-se por apresentar evoluções morfológicas sobre o hospedeiro, onde são discerníveis os estádios de larvas, ninfas e adultos (GONZALES,1993). Nesta fase, a dependência em relação ao hospedeiro e a necessidade de fixação em partes do corpo que permitam um maior índice de sobrevivência, fazem com que haja uma competição de ixodídeos por nichos similares (MATTHYSSE, 1984). A competição intraespecífica, durante a fase parasitária do ciclo de vida do Boophilus microplus, é possivelmente um mecanismo regulador da população de carrapatos (SUTHERST et al., 1973). Com o objetivo de verificar a ocorrência de competição nessa espécie de carrapato, e corroborar a correlação positiva entre o peso da fêmea ingurgitada e o peso da massa de ovos por ela produzida, realizou-se o presente trabalho.

\section{MATERIAL E MÉTODOS}

Estudo da competição intra-específica de Boophilus microplus: Os experimentos foram realizados no Campo Experimental de Coronel Pacheco - Embrapa Gado de Leite, no Município de Coronel Pacheco, na região da Zona da Mata de Minas Gerais, Brasil.

\footnotetext{
${ }^{1}$ Parte da dissertação de Mestrado apresentada pelo primeiro autor à Universidade Federal de Juiz de Fora (UFJF), Juiz de Fora, MG. ${ }^{2}$ Biólogo, MSc.

${ }^{3}$ Médico Veterinário, Doutor, Pesquisador da Embrapa Gado de Leite, Rua Eugênio do Nascimento 610, 36038-330, Juiz de Fora, MG. E-mail: John@cnpgl.embrapa.br. Autor para correspondência.
} 
Experimento 1: infestação natural. $O$ experimento foi desenvolvido durante os meses de novembro e dezembro de 2000. Foram utilizadas três vacas, 7/8 Holandês X Zebu $(87 \%$ de sangue europeu), de aproximadamente dois anos de idade, mantidas por 24 meses em pastagem de Brachiaria decumbens infestada com larvas do carrapato $\boldsymbol{B}$. microplus, e reconhecidas por brincos de identificação. As vacas, naturalmente infestadas e com alto grau de infestação, foram transferidas para baias individuais, isentas de carrapato e com piso ripado, onde permaneceram até a queda das fêmeas ingurgitadas. Estas foram recolhidas diariamente e levadas ao laboratório para serem lavadas, secadas, contadas e pesadas em balança analítica. Quando o número de fêmeas ingurgitadas, recolhidas da baia de cada vaca, era igual ou menor que 150, todas eram pesadas. Acima de 150, apenas 100 fêmeas escolhidas aleatoriamente eram pesadas.

Nos experimentos de infestação artificial (experimentos 2, 3 e 4), foram utilizados bezerros 15/16 Holandês X Zebu (94\% de sangue europeu), de aproximadamente um ano de idade, identificados por brincos numerados e com experiência prévia com carrapatos. Os animais utilizados ficavam em baia coletiva e estavam livres de carrapato. Cada infestação foi feita com aproximadamente 16.000 larvas, originadas de $0,8 \mathrm{~g}$ de ovos, segundo SUTHERST et al. (1978b) e GONZALES (1993). Durante a infestação, as larvas foram distribuídas sobre o dorso dos bezerros, que tiveram a sua cauda amarrada e foram impedidos de se lamber durante 90 minutos. HITCHCOOK (1955a) e ROBERTS (1968) observaram que as primeiras fêmeas ingurgitadas caem no $19^{\circ}$ dia de infestação. Portanto, 18 dias após a infestação, os bezerros foram confinados nas baias individuais, seguindo o procedimento do experimento 1 .

Experimento 2: infestação artificial única. Foi desenvolvido durante o mês de outubro de 2000. Foram utilizados dois bezerros e cada um deles recebeu uma única infestação.

Experimento 3: infestação artificial tripla, com intervalo de 5 dias. $\mathrm{O}$ experimento foi desenvolvido durante os meses de agosto e setembro de 2000. Foram utilizados três bezerros e cada um recebeu três infestações, com um intervalo de 5 dias entre uma infestação e outra. Assim sendo, cada animal recebeu uma carga total de 48.000 larvas.

Experimento 4: infestação artificial tripla, com intervalo de três dias. Foi desenvolvido durante o mês de maio de 2000. Foram utilizados dois bezerros e cada um recebeu três infestações, com um intervalo de três dias entre uma infestação e outra. A carga total foi de 48.000 larvas por bezerro. Para análise estatística dos quatro experimentos descritos, utilizou-se a análise de variância.

Estudo dos índices de eficiência reprodutiva e nutricional: As 660 fêmeas ingurgitadas utilizadas no experimento foram divididas em três grupos: pequenas (P) (fêmeas pesando até $0,199 \mathrm{~g}$ ), médias $(\mathrm{M})$ (fêmeas pesando entre 0,200 e $0,299 \mathrm{~g}$ ) e grandes $(\mathrm{G})$ (fêmeas pesando acima de 0,299g). Foram anotadas as datas individuais de início e fim de postura. Para detecção da data final de postura, a partir do $10^{\circ}$ dia, os ovos foram removidos diariamente do gnatossoma, em função deste ser o menor valor encontrado na literatura (FURLONG, 1990), relacionado ao período de postura. Ao final da postura, as fêmeas foram pesadas para obtenção do chamado peso residual (ou peso final). A massa de ovos também foi pesada. Os registros de peso da fêmea ingurgitada no início e ao final da postura, forneceram a perda de peso durante a postura. Esses dados, juntamente com o peso da postura, permitiram que se calculassem os índices de eficiência reprodutiva (IER = massa de ovos X 100 / peso inicial da fêmea ingurgitada) e nutricional (IEN = massa de ovos X $100 /$ perda de peso da fêmea ingurgitada), de acordo com BENNETT (1974). As anotações de datas de queda de fêmeas ingurgitadas e de início de postura das mesmas, forneceram o período de pré-postura, e as anotações de início e fim de postura, forneceram o período de postura.

$\mathrm{Na}$ análise estatística desse experimento, foi utilizado o teste não-paramétrico de KruskalWallis.

\section{RESULTADOS / DISCUSSÃO}

Experimento 1: infestação natural. Apresenta-se na figura 1, o resultado da análise de variância, no modelo quadrático, da média de peso das fêmeas ingurgitadas recuperadas dos animais, a qual apresentou a equação $\hat{Y}=0,150536+0,008155 X-$ $0,000234 X^{2}$, com $R^{2}=0,77$, onde se percebe $\mathrm{o}$ aumento do peso médio das fêmeas ingurgitadas de B. microplus no decorrer dos 24 dias de queda. Pode-se observar a superposição dos valores obtidos e dos estimados, em decorrência do coeficiente de regressão encontrado $\left(\mathrm{R}^{2}=0,77\right)$. A média de peso das fêmeas ingurgitadas foi aumentando à medida que se aproximava o último dia do período de queda. Estas observações sugerem que as últimas larvas a subirem no hospedeiro sofreram um menor grau de competição, pois com o passar dos dias, o bovino apresentava quantidades cada vez menores de 


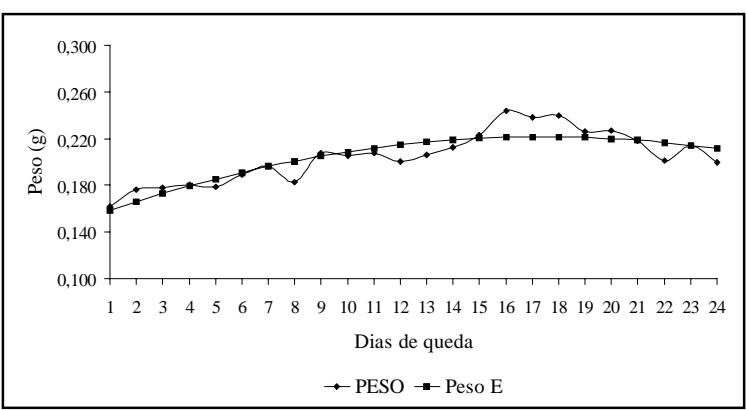

Figura 1 - Valores observados (PESO) e estimados (Peso E) por análise de variância, do peso médio de fêmeas ingurgitadas de Boophilus microplus recuperadas de três vacas infestadas naturalmente, em função dos dias de queda durante o período de 10 de novembro a 3 de dezembro de 2000, no Campo Experimental de Coronel Pacheco - Embrapa Gado de Leite, Coronel Pacheco, MG, Brasil.

carrapato. No caso da infestação natural, todos os dias larvas de carrapato sobem no bovino e fêmeas ingurgitadas caem no pasto. Com isso, todas as larvas, independente da época em que subiram no bovino, provavelmente tiveram as mesmas chances na seleção do local de implantação no hospedeiro. Porém, a partir do momento em que os bovinos foram levados do pasto para as baias individuais, outras larvas deixaram de infestar esses animais e isso parece ter favorecido as últimas larvas que subiram no hospedeiro. Quanto menor o número de competidores ocupando o habitat ideal, mais vantajoso ele se torna (KREBS \& DAVIES, 1996). A provável redução da competição influenciou no ingurgitamento das fêmeas, fazendo com que elas aumentassem o seu peso.

Experimento 2: infestação artificial única. Apresentam-se na figura 2 , as médias de peso de fêmeas ingurgitadas, recuperadas dos dois

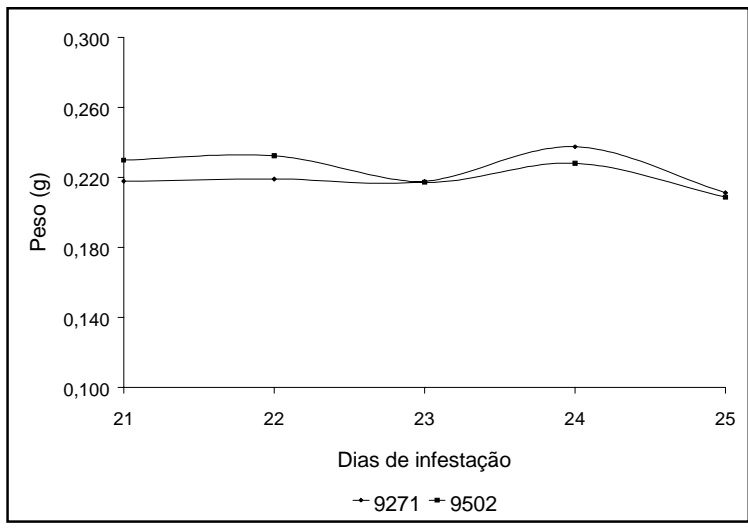

Figura 2 - Médias de peso de fêmeas ingurgitadas recuperadas de dois bezerros infestados uma única vez (9271 e 9502), em função dos dias de queda durante o período de 22 a 26 de outubro de 2000, no Campo Experimental de Coronel Pacheco - Embrapa Gado de Leite, Coronel Pacheco, MG, Brasil. bezerros (que receberam uma única infestação) em função dos dias de queda durante o período de 22 a 26 de outubro de 2000. A análise de variância da média de peso das fêmeas ingurgitadas, em função dos dias de queda, não apresentou regressão, uma vez que o peso médio se manteve constante no decorrer dos 5 dias de queda. Foi observado que a média de peso das fêmeas ingurgitadas manteve um equilíbrio durante o período de queda, o que sugere que as larvas tiveram as mesmas chances na procura dos locais preferenciais para fixação no hospedeiro, uma vez que os bovinos encontravam-se isentos de carrapato antes de receberem a única infestação do experimento.

Experimento 3: infestação artificial tripla, com intervalo de 5 dias. Apresenta-se na figura 3, o resultado da análise de variância, no modelo linear, da média de peso de fêmeas ingurgitadas recuperadas dos animais que receberam três infestações com 5 dias de intervalo. Essa média apresentou a equação $\hat{Y}=0,241071-0,002591 X$, com $\mathrm{R}^{2}=0,71$, onde se percebe a redução do peso médio das fêmeas ingurgitadas de B. microplus no decorrer dos 18 dias de queda. Pode-se observar a superposição dos valores obtidos e dos estimados, em decorrência do coeficiente de regressão encontrado $\left(R^{2}=0,71\right)$. Essa análise sugere que as larvas da primeira infestação migraram à procura dos locais preferenciais e se fixaram. Com isso, as larvas da segunda infestação e, principalmente as da terceira infestação, provavelmente tiveram uma certa desvantagem na competição por locais mais adequados para fixação e conseqüentemente ficaram mais expostas à lambedura, aos movimentos enérgicos da cauda do hospedeiro e ao ato de se coçar a fim de se livrar do parasito, ocasionando o

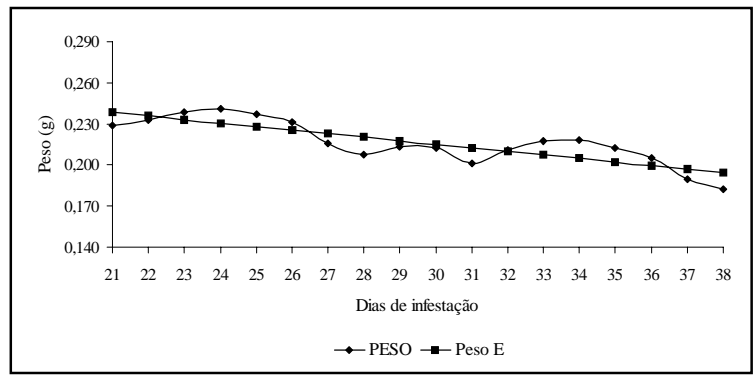

Figura 3 - Valores observados (PESO) e estimados (Peso E) por análise de variância, do peso médio de fêmeas ingurgitadas de Boophilus microplus recuperadas de três bezerros que receberam três infestações com 5 dias de intervalo, em função dos dias de queda durante o período de 1 a 18 de setembro de 2000, no Campo Experimental de Coronel Pacheco - Embrapa Gado de Leite, Coronel Pacheco - MG, Brasil. 
desprendimento precoce de fêmeas semiingurgitadas. De acordo com MORELLI JÚNIOR (2000), a histamina liberada por células dos tecidos conjuntivos do hospedeiro tem ação irritante e resulta em reação alérgica local, provocando coceira, além de inibir a salivação e o ingurgitamento de carrapatos. BINTA et al. (1984), citado por MORELLI JÚNIOR (2000), observaram níveis elevados de histamina em gado resistente ao carrapato B. microplus. CORDOVÉS (1996) afirma que muitas espécies de hospedeiros costumam limpar-se de ectoparasitos, lambendo-se, raspandose com as patas ou contra alguns objetos. Outro fator que pode ter contribuído para o desprendimento de certos exemplares foi a diminuição do espaço existente entre os parasitos, provocada pelo aumento do volume das fêmeas ao se tornarem repletas, estando estas observações de acordo com CORDOVÉS (1996).

Experimento 4: infestação artificial tripla, com intervalo de três dias. Apresenta-se, na figura 4, o resultado da análise de variância, no modelo linear, da média de peso de fêmeas ingurgitadas recuperadas de dois bezerros que receberam três infestações com três dias de intervalo. A análise apresentou a equação $\hat{\mathrm{Y}}=0,258687-0,004679 \mathrm{X}$, com $\mathrm{R}^{2}=0,87$, onde se percebe a redução do peso médio das fêmeas ingurgitadas de $\boldsymbol{B}$. microplus no decorrer dos 10 dias de queda. Pode-se observar a superposição dos valores obtidos e dos estimados, em decorrência do elevado coeficiente de regressão encontrado $\left(\mathrm{R}^{2}=0,87\right)$. O resultado desse experimento foi muito parecido com o resultado observado no experimento 3. Entretanto, aqui a competição pareceu mais intensa. Talvez isso se explique pelo fato do intervalo entre as infestações desse experimento (três dias) ter sido menor que o intervalo do experimento anterior (5 dias). Nos experimentos de infestação artificial, os bovinos estavam isentos de carrapato até receberem a primeira infestação. Sendo assim, as larvas da primeira infestação tiveram maior oportunidade na procura por locais mais adequados para fixação (quando comparadas às larvas da segunda e terceira infestação) por percorrerem um hospedeiro sem carrapato algum. SUTHERST et al. (1978a) observaram que nos hospedeiros com experiência prévia com $\boldsymbol{B}$. microplus, quando a infestação é alta, o estímulo da autolimpeza é maior, resultando em maior proporção de carrapatos removidos.

Durante a coleta das fêmeas ingurgitadas, muitas vezes foi flagrada a queda de várias fêmeas no exato momento em que o bovino se coçava. Foi

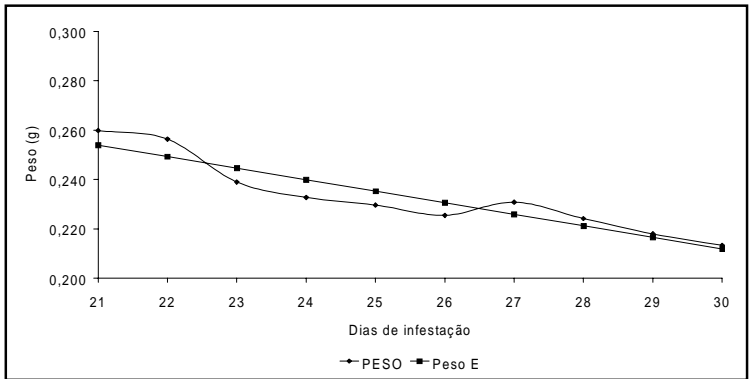

Figura 4 - Valores observados (PESO) e estimados (Peso E) por análise de variância, do peso médio de fêmeas ingurgitadas de Boophilus microplus recuperadas de dois bezerros que receberam três infestações com três dias de intervalo, em função dos dias de queda durante o período de 22 a 31 de maio de 2000, no Campo Experimental de Coronel Pacheco - Embrapa Gado de Leite, Coronel Pacheco - MG, Brasil.

observada uma migração preferencial do parasito para determinadas regiões do corpo dos bovinos, tais como: entrepernas, tábua do pescoço, barbela e base da cauda. Os locais mais requisitados para fixação dos carrapatos no hospedeiro foram os mesmos citados por autores como PALMER et al. (1976) e GONZALES (1993). Segundo SONENSHINE (1991), o sucesso da alimentação depende da habilidade do parasito em superar o sistema de defesa do hospedeiro e, de acordo com PEREIRA (1982), a autolimpeza (defesa por lambedura, pelo ato de se coçar, ou pela fricção de encontro a paredes ou outras superfícies) é um dos componentes mais importantes da resistência do bovino.

É evidente que a competição influi na distribuição dos carrapatos sobre o hospedeiro (CORDOVÉS,1996). Nos experimentos 3 e 4, o provável aumento da competição influenciou o ingurgitamento das fêmeas, impedindo que elas aumentassem seus pesos. Trabalhando com três espécies diferentes do gênero Boophilus, MATTHYSSE (1984) afirma que a dependência em relação ao hospedeiro e a necessidade de fixação em locais de maior índice de sobrevivência, faz com que haja uma competição entre essas espécies por nichos semelhantes. Quanto maior o número de competidores que passam a ocupar o habitat mais favorável, mais os recursos são reduzidos e menos vantajoso ele se torna para os que ali chegam (KREBS \& DAVIES, 1996). Assim, os últimos são forçados a procurar por locais menos privilegiados, porque neles haverá menor competição. 
Experimento 5: influência do peso de fêmeas ingurgitadas na produção de ovos. Os resultados encontram-se descritos na tabela 1.

Considerando-se o peso, $39 \%$ das fêmeas ingurgitadas pertenciam ao grupo $\mathrm{G}$ (fêmeas pesando acima de $0,299 \mathrm{~g}$ ), $35 \%$ ao grupo $\mathrm{M}$ (fêmeas
LONDT (1974), com Boophilus decoloratus, de que o tempo despendido com a pré-postura não tem relação com o peso da fêmea ingurgitada.

Em relação ao período de postura, o resultado confirma as observações feitas por BENNETT (1974) de que, sob a mesma

Tabela 1 - Peso médio $(\mathrm{g})$, comprimento $(\mathrm{cm})$, largura $(\mathrm{cm})$, peso da massa de ovos $(\mathrm{g})$, período de pré-postura (dias), período de postura (dias), índice de eficiência reprodutiva (\%), índice de eficiência nutricional (\%) e respectivos desvios-padrão (DP) de fêmeas ingurgitadas de Boophilus microplus, amostradas por grupos: G, grandes; M, médias; P, pequenas.

\begin{tabular}{|c|c|c|c|c|c|c|c|c|c|c|c|c|c|c|c|c|}
\hline \multirow[t]{2}{*}{ Grupos } & \multicolumn{2}{|c|}{ Peso } & \multicolumn{2}{|c|}{ Comprimento } & \multicolumn{2}{|c|}{ Largura } & \multicolumn{2}{|c|}{ Peso ovos } & \multicolumn{2}{|c|}{ Pré-postura } & \multicolumn{2}{|c|}{ Postura } & \multicolumn{2}{|c|}{ IER } & \multicolumn{2}{|c|}{ IEN } \\
\hline & $\mathrm{g}$ & DP & $\mathrm{cm}$ & DP & $\mathrm{cm}$ & DP & g & DP & dias & DP & dias & DP & $\%$ & DP & $\%$ & DP \\
\hline G & $0,331^{\mathrm{a}}$ & 0,028 & $1,12^{\mathrm{a}}$ & 0,058 & $0,78^{\mathrm{a}}$ & 0,046 & $0,169^{\mathrm{a}}$ & 0,031 & $3,74^{\mathrm{a}}$ & 0,570 & $12,6^{a *}$ & 2,160 & $51,1^{\mathrm{a}}$ & 8,73 & $70,2^{\mathrm{a}}$ & 7,56 \\
\hline M & $0,241^{\mathrm{b}}$ & 0,026 & $1,01^{\mathrm{b}}$ & 0,064 & $0,68^{\mathrm{b}}$ & 0,044 & $0,116^{\mathrm{b}}$ & 0,032 & $3,80^{\mathrm{a}}$ & 0,666 & $12,1^{b *}$ & 2,151 & $47,8^{\mathrm{b}}$ & 11,83 & $66,9^{\mathrm{b}}$ & 10,83 \\
\hline $\mathrm{P}$ & $0,158^{\mathrm{c}}$ & 0,028 & $0,88^{\mathrm{c}}$ & 0,065 & $0,60^{\mathrm{c}}$ & 0,046 & $0,072^{\mathrm{c}}$ & 0,023 & $3,63^{\mathrm{a}}$ & 0,845 & $11,4^{\mathrm{c} *}$ & 1,820 & $45,7^{\mathrm{c}}$ & 11,29 & $63,3^{\mathrm{c}}$ & 12,40 \\
\hline
\end{tabular}

Letras diferentes na mesma coluna implicam diferença estatística significativa $(\mathrm{p}<0,01)$.

$*(\mathrm{p}<0,05)$

pesando entre 0,200 e $0,299 \mathrm{~g}$ ) e $26 \%$ das fêmeas ingurgitadas pertenciam ao grupo $\mathrm{P}$ (fêmeas pesando até $0,199 \mathrm{~g}$ ). Sabendo-se que $1 \mathrm{~g}$ de ovos de $\boldsymbol{B}$. microplus tem cerca de 20.000 ovos (SUTHERST $\boldsymbol{e} t$ al., 1978b; GONZALES 1993), pode-se afirmar que a média do número de ovos postos pelas fêmeas do grupo $\mathrm{G}$ foi de aproximadamente 3.380 ovos, do grupo $\mathrm{M}$ foi de 2.320 ovos, e do grupo $\mathrm{P}$ foi de 1.440 ovos. Assim, conclui-se que as fêmeas ingurgitadas do grupo $\mathrm{M}$ puseram uma quantidade menor de ovos, cerca de $33 \%$ a menos, do que as fêmeas do grupo G. As fêmeas ingurgitadas do grupo $\mathrm{P}$ colocaram uma quantidade ainda menor de ovos, cerca de $57 \%$ a menos, quando comparadas às fêmeas do grupo G. Tal resultado vem confirmar a correlação positiva entre $o$ peso da fêmea ingurgitada e o número de ovos postos.

Com relação ao índice de eficiência reprodutiva (IER), podemos afirmar que o peso esperado da massa de ovos de uma fêmea ingurgitada do grupo $\mathrm{G}$, é maior do que o peso esperado da massa de ovos de uma fêmea do grupo M. Esse por sua vez é maior do que o peso esperado da massa de ovos de uma fêmea do grupo P. Quanto ao índice de eficiência nutricional, as fêmeas ingurgitadas do grupo $\mathrm{G}$ demonstraram maior grau de eficiência no processo de conversão do alimento ingerido em massa de ovos.

As médias encontradas, do período de pré-postura, estão dentro dos padrões citados por autores como HITCHCOCK (1955b), GONZALES (1975) e ALVARADO \& GONZALES (1979). O fato de não haver diferença significativa entre elas sustenta a afirmação feita por DRUMMOND et al. (1971), trabalhando com Amblyomma americanum, e temperatura, fêmeas maiores e mais pesadas encerram a sua postura num maior intervalo de tempo, porque possuem maior quantidade de nutrientes para converter em massa de ovos, e por isso só terminam a postura depois das fêmeas menores. As médias encontradas estão dentro dos valores citados por HITCHCOCK (1955b), que em seu experimento obteve um resultado de 11 a 16 dias de postura. BENNETT (1974) afirmou que o peso da fêmea ingurgitada tem uma relação direta com o sucesso de sua fase de vida parasitária. Portanto, se o aumento da competição pode fazer com que haja uma diminuição no peso das fêmeas ingurgitadas, consequentemente haverá também um menor grau de eficiência no processo de conversão do alimento ingerido em massa de ovos porque, de acordo com esse autor, o potencial de oviposição de uma fêmea ingurgitada está diretamente relacionado a sua capa cidade alimentar.

\section{CONCLUSÕES}

O número de competidores influencia o peso médio das fêmeas. O peso das fêmeas é diretamente proporcional ao comprimento e largura. Há uma correlação positiva entre o peso da fêmea ingurgitada e o número de ovos postos. Fêmeas mais pesadas têm maior eficiência reprodutiva $\mathrm{e}$ nutricional. Ao contrário do período de pré-postura, o período de postura está relacionado ao peso da fêmea ingurgitada.

\section{REFERÊNCIAS BIBLIOGRÁFICAS}

ALVARADO, R.U., GONZALES, J.C. A postura e a viabilidade do Boophilus microplus (Canestrini, 1887) (Acarina, Ixodidae) em 
condições de laboratório. Revista Latino-Americana de Microbiologia, Mexico DF., v.21, p.31-36, 1979.

BENNETT, G.F. Oviposition of Boophilus microplus (Canestrini, 1887) (Acarina: Ixodidae). I. Influence of tick

DRUMMOND, R.O., WHETSTONE, T.M., GLADNEY, W.J. Oviposition of the Lone Star Tick. Annals of Entomological Society of America, Lawrence, v.64, n.1, p.191-194, 1971.

FURLONG, J. Comportamento de Boophilus microplus (Canestrini, 1887) e Amblyomma cajennense (Fabricius, 1787) em infestações consecutivas ou simultâneas em bovinos: análise preliminar de parâmetros biológicos. Rio de Janeiro, RJ, 1990. 92p. Tese (Doutorado em Medicina Veterinária) - Instituto de Biologia, Universidade Federal Rural do Rio de Janeiro, 1990.

GONZALES, J.C. O controle dos carrapatos dos bovinos. Porto Alegre : Sulina, 1975. 104p.

GONZALES, J.C. O controle do carrapato do boi. Porto Alegre : Mestre Jou, 1993. 79p.

HITCHCOCK, L.F. Studies on the parasitic stages of the cattle ticks, Boophilus microplus (Canestrini) (Acarina: Ixodidae). Australian Journal of Zoology, Collingwood, v.3, p.145$155,1955 \mathrm{a}$.

HITCHCOCK, L.F. Studies on the non-parasitic stages on the cattle tick, Boophilus microplus (Canestrini) (Acarina: Ixodidae). Australian Journal of Zoology, Collingwood, v.3, p.295-311, 1955b

KREBS, J.R., DAVIES, N.B. Introdução à ecologia comportamental. São Paulo : Atheneu, 1996. 420p.

LONDT, J.G.H. The preoviposition period of Boophilus decoloratus (Koch, 1844) (Acarina: Ixodidae). Journal of Entomological Society of Southeastern Africa, v.37, p.405-412, 1974.

MATTHYSSE, J.G. Recent changes in relative abundance and distribution of Boophilus decoloratus, B. geigyi and B. annulatus (Ixodoidea: Ixodidae) in Mali, West Africa. Acarology VI, Amsterdan, v.2, p.1247-1251, 1984.

MORELLI JÚNIOR, J. Reação de hipersensibilidade cutânea em bovinos Bos taurus e Bos indicus ao carrapato Boophilus microplus (Acarina: Ixodidae). Jaboticabal, SP, 2000. 96p. Dissertação (Mestrado em Medicina Veterinária) - Faculdade de Ciências Agrárias e Veterinárias, Universidade Estadual Paulista, 2000

PALMER, W.A., TREVERROW, N.L., O'NEIL, G.H. Factors affecting the detection of infestations of Boophilus microplus in tick control programs. Australian Veterinary Journal, Collingwood, v.52, p.321-324, 1976.

PEREIRA, M.C. Boophilus microplus (Canestrini, 1887): revisão taxionômica e morfo-biológica. Rio de Janeiro : Quimio, 1982. 105p.

ROBERTS, J.A. Resistance of cattle to the tick Boophilus microplus (Canestrini). I. Development of ticks on Bos taurus. Journal of Parasitology, Winston-Salem, v.54, n.4, p.663666, 1968.

SONENSHINE, D.E. Biology of ticks. New York : Oxford University, 1991. V.1, 447p. size on egg production. Acarologia, Paris, v.16, n.1, p.52-61, 1974.

CORDOVÉS, C.O. Carrapato: controle ou erradicação. Alegrete : Gralha, 1996. 130p.

SUTHERST, R.W., UTECH, K.B.W., DALLWITZ, M.J., et al. Intra-specific competition of Boophilus microplus (Canestrini) on cattle. Journal of Applied Ecology, Oxford, v.10, p.855-862, 1973.

SUTHERST, R.W., WAGLAND, B.M., ROBERTS, J.A. The effect of density on the survival of Boophilus microplus on previously unexposed cattle. International Journal of Parasitology, Oxford, v.8, p.321-324, 1978a.

SUTHERST, R.W., WHARTON, R.H., UTECH, K.B.W. Guide to studies on tick ecology. Melbourne : Division of Entomology. CSIRO, 1978b. V.14, p.1-59. (Technical Paper). 